\title{
Ace Project As A Project Management Tool
}

\author{
Melinda Cline, Georgia Gwinnett College, USA \\ Carl S. Guynes, University of North Texas, USA \\ Karine Simard, Websystems, Canada
}

\begin{abstract}
The primary challenge of project management is to achieve the project goals and objectives while adhering to project constraints - usually scope, quality, time and budget. The secondary challenge is to optimize the allocation and integration of resources necessary to meet pre-defined objectives. Project management software provides an active learning component to the study of project management principles. Prior literature indicates that active learning contributes to student success when students are actively engaged both inside and outside the classroom.
\end{abstract}

Keywords: Project Management, AceProject, Educational Software, Online Learning

\section{INTRODUCTION}

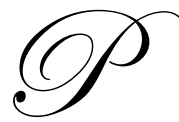

roject management is the application of knowledge, skills, tools and techniques to project activities to meet project requirements (Project Management Institute, 2008). It is the discipline of planning, organizing, and managing resources for the successful completion of specific project goals and objectives. A project has a specific start and completion date and is undertaken to create a unique product or service which brings about beneficial change or added value. The primary challenge of project management is to achieve the project goals and objectives while adhering to project constraints - usually scope, quality, time and budget. The secondary challenge is to optimize the allocation and integration of resources necessary to meet pre-defined objectives. A project includes a carefully defined set of activities that use resources (money, people, materials, energy, space, provisions, communication, motivation, etc.) to achieve the project goals and objectives (Wikipedia, 2008). Project management software provides a set of tools to help identify and monitor project activities.

Project management software provides an active learning component to the study of project management principles. Prior literature indicates that active learning contributes to student success when students are actively engaged both inside and outside the classroom (Astin, 1993; Chickering \& Gamson, 1987; Pascarella \& Terenzini 2005). Typically, the software tool used to support the instruction of project management concepts is Microsoft Project. For some schools, however, this tool may be cost prohibitive.

\section{BACKGROUND OF THE STUDY}

While teaching at a small, private university the researcher(s) were faced with the dilemma of delivering an effective online project management course with no budget for project management software. The school did have an educational software contract with Microsoft, but it did not include licenses for Microsoft Project. In an effort to acquire a tool, the researcher(s) requested and generously received a grant from Websystems, Inc to provide students access to the AceProject project management software. This tool provides students with the ability to gain hands-on knowledge of the project management software currently used by major corporations and universities in 21 countries including AT\&T, Black \& Decker, Cogent Systems, E*TRADE Financial, Kaiser Permanente, The University of Texas at Austin, Pearson Education Technologies, and IBM Canada. Access to the web-based software is provided to students free of charge under the grant.

\section{ACEPROJECT SOFTWARE}

From an instructional point of view, Ace Project software is convenient to set-up and requires no resources from campus computing services. AceProject's project management software is an Internet-based application 
maintained by Websystems, inc with the data kept securely on their servers. Once the instructor has access, he/she or a teaching assistant sets up individual user accounts for each student. On average, this takes less than a minute per student. Figure 1 depicts the initial login screen.

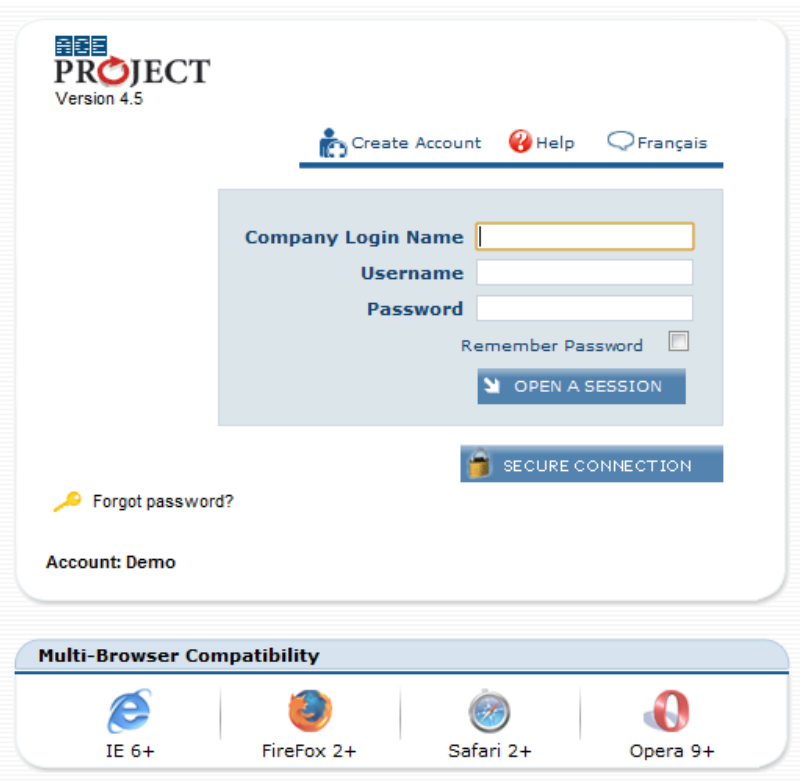

Figure 1: Login Screen

Students and instructors can review and update projects at will using any computer with access to the Internet. There is no software for the student to install or maintain and the software is designed to be easy to use. There are extensive Help facilities and even instructional videos. Project pages are easy to browse, information is presented one form at a time, and each form supports a sort function on the column headers. Gantt charts and other project and resource reports are available. Figure 2 provides an illustration of a Gantt chart.

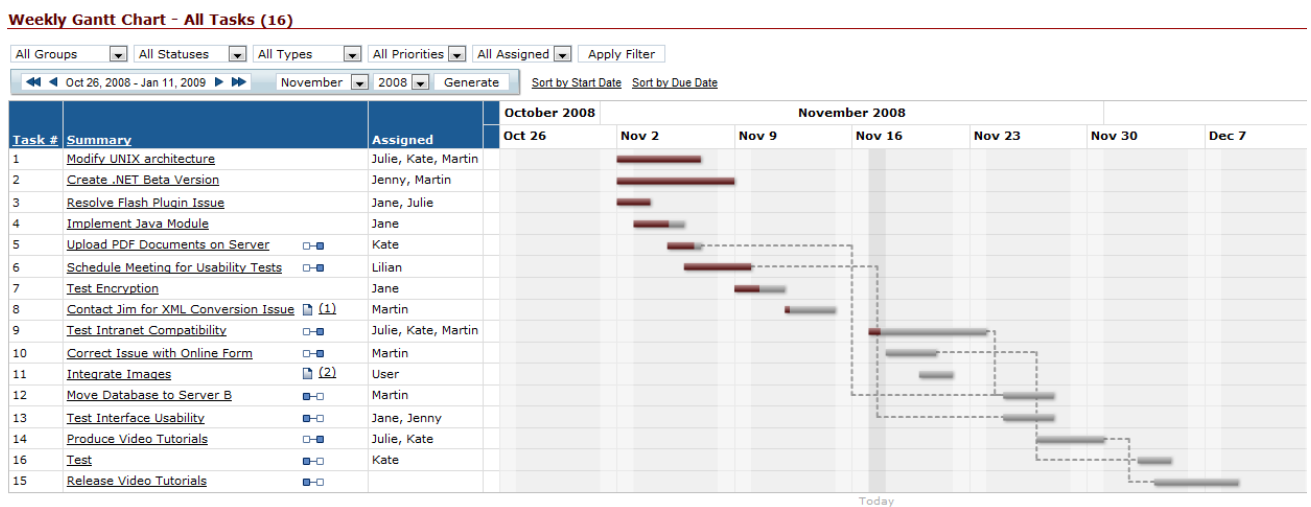

Figure 2: Gantt Chart

\section{ACEPROJECT ASSIGNMENTS}

Students used the software in online courses covering project management and other IT management topics. The assignments required that the student prepare a detailed list of tasks required for a successful academic semester, with a focus on time management. The assignment was given early in the semester and required the student to make periodic updates. Figure 3 provides a sample illustration of a project task list. 


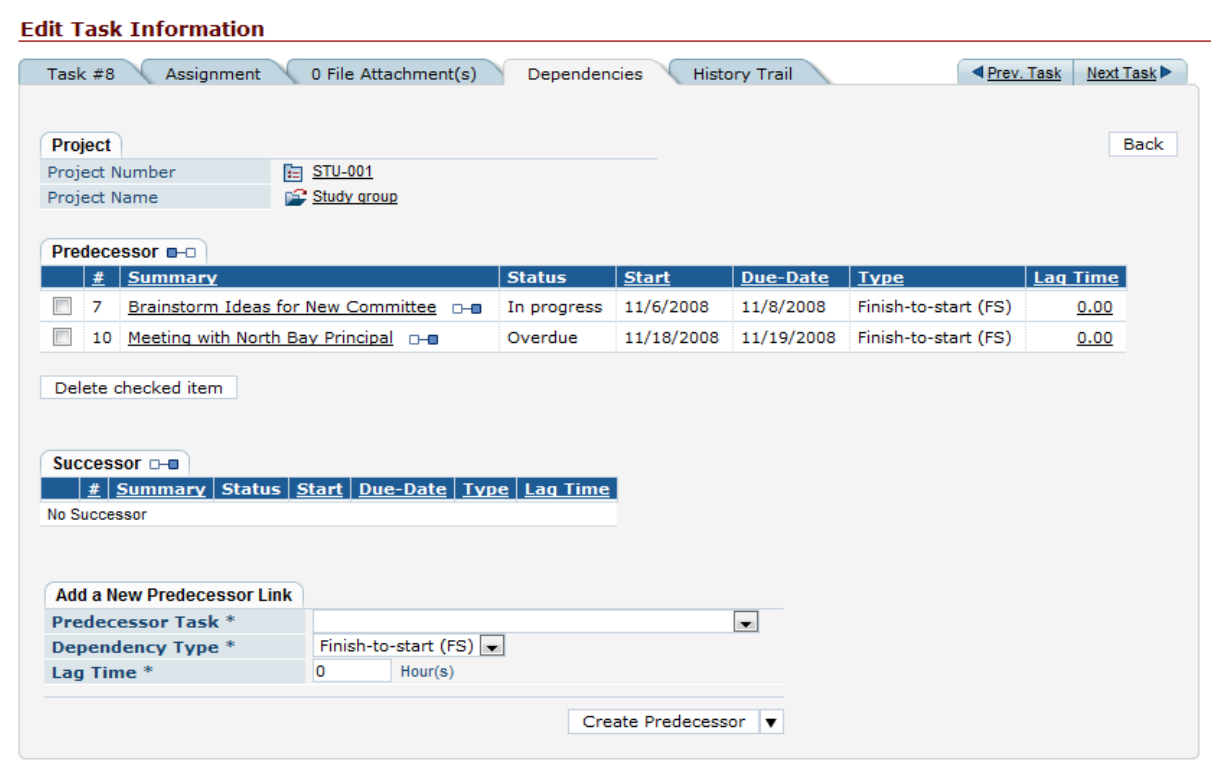

Figure 3: Project Task List

To get started, each student received an e-mail from the instructor generated by AceProject. The designated Administrator (the instructor) identified the student to the school's AceProject account. The generated e-mail included the account name, user id, password, and connection instructions. The account name was determined by AceProject based on the school's name, but the user name and password were entered by the instructor so they could match the student's e-mail id and student number. The issuance of userids and passwords in AceProject was a very smooth process. Figure 4 shows the User Information screen used by the instructor to identify students to the account. Fields marked with an asterisk $(*)$ are required.

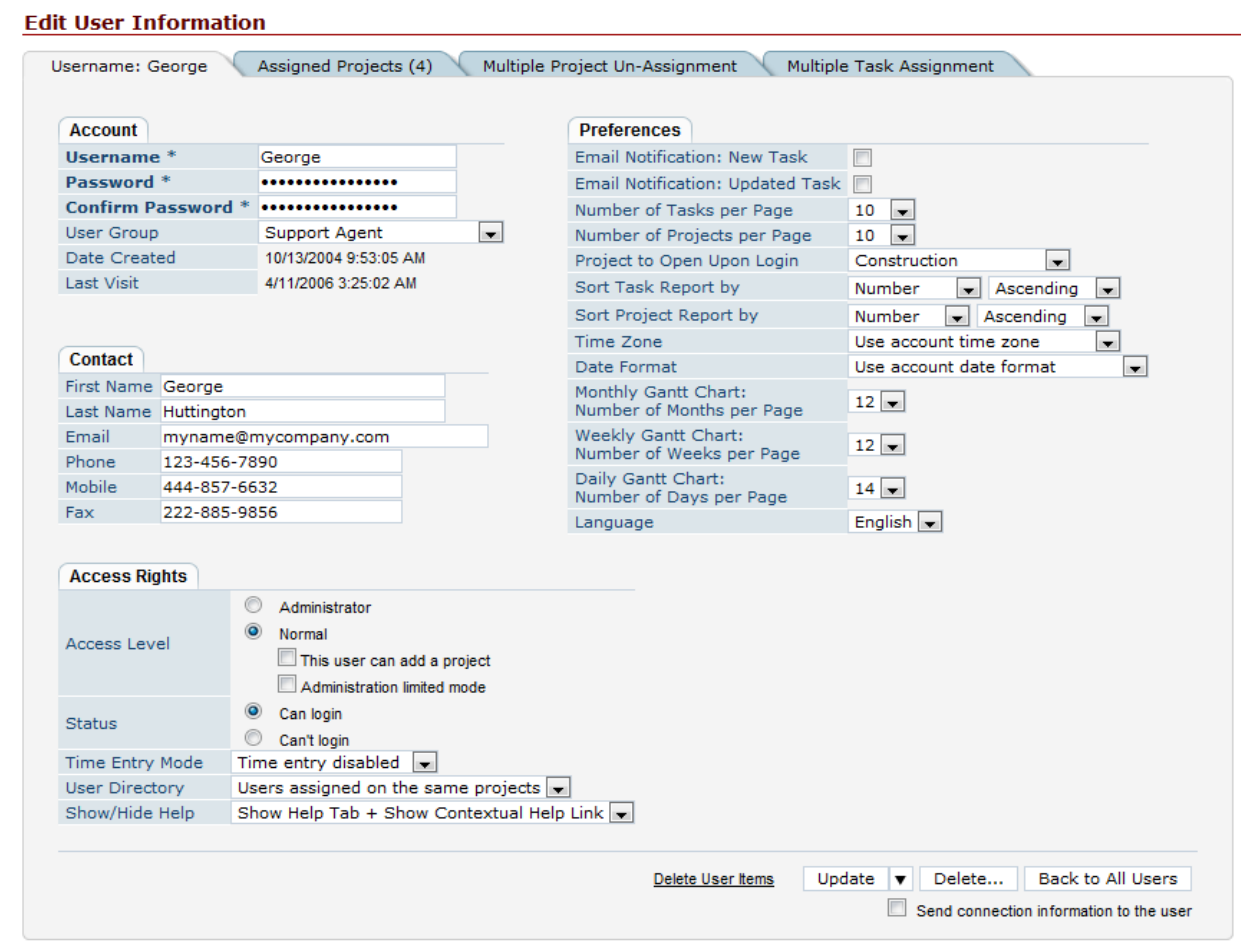

Figure 4: User Information Screen 
The assignments had three components: learning to use the AceProject project management software, effective creation of a project, and documenting the student's impression of using the software. To be sure students used the software sufficiently to be able to effectively form an opinion, they were required to enter at least 50 tasks with varying dates and at least 5 tasks were required to have dependencies. Students documented their impression of using the software. As is usually the case, some students were very brief while others provided extensive comments. As a part of the assignment, students were asked to describe the strengths, weaknesses, and challenges of using AceProject. The next section discusses their comments in detail.

\section{STUDENT COMMENTS}

Learning to use the software was relatively easy for most students; however, some students felt it necessary to come in for an office visit to get started. Had the classes been traditional, a one-session demonstration would have been adequate for most students. The AceProject website has extensive instructions covering how to use the software, including videos. The software is menu driven with a well-developed Help facility. Most students learned to use the software on their own, although several students commented on the difficulty of learning a new software tool by themselves. Sample comments include:

"Once I got the hang of it, it was easy to use."

“...instructions were clear.”

"This software is easy to learn how to use."

"The tool had easy-to-use screens and I was able to maneuver through each screen without difficulty."

"I found the AceProject tool to be a little bit confusing at first. But once I read all of the info on the Help tab and got started it started to flow."

"The standard template seemed to be the easiest and fastest way to start."

"My first impression of AceProject was that it was intimidating. The user interface is a bit overwhelming at first. After I really sat down and committed myself to figuring it out it was pretty straightforward and easy to use."

Once students got started with the software they were able to understand the benefits. The real-time Gantt chart showing tasks and dates as they are entered is very helpful. Student comments on the benefits of the software include:

"Being able to group different tasks keep them organized."

"I liked being able to change the task types to fit my project."

"AceProject allows the project manager to give specific instructions and include important attachments to the files for all persons assigned to that specific task. What I unique about this feature is that it sends messages to all persons involved simultaneously."

"AceProject can be used for every type of project, from construction to event planning."

"...AceProject is a clean and efficient way to manage information and provide instructions to staff."

"There are many useful tools with each project such as calendar, time reporting, task reports, Gantt charts, and statistical information."

"It was nice to be able to pull up a calendar and see exactly where you were in terms of time remaining to complete the tasks assigned." 
"Some of the strengths with this program would be the ability to change the logo to a company logo, being able to assign different tasks to different persons in other time zones, being web-based allows for easy access, and the different reports that can be developed."

The students did find areas for improvement. Many of these comments demonstrate that students not only learned how to use the software, but also understood its purpose thoroughly. Many students were able to make detailed comments about how the application could be improved. Comments included:

"There need to be dropdown lists on the task list screen for easier changes."

"Had trouble with recurring tasks and adding a new task between existing tasks (rather than at the end of tasks)."

"Not able to modify/add attachments to tasks after they had been marked as complete."

"The program notifies by e-mail of changes [to new and existing tasks] but it does not seem to have a way to set up a reminder for updating after tasks are done."

"The only thing that I would change would be to try to implement this program on a Blackberry. That way you will always know what's coming and what needs to be planned."

"One feature that might make the program more useful would be some kind of e-mail notification system for upcoming tasks."

Overall, the students liked the software and the assignments requiring them to use it. Comments included:

"Thanks for giving this project to me. I thought it was fun and better than doing some other stuff."

"Overall, I got a pretty good idea on how to use it and what is was used for."

"I can see where this would be a valuable tool for business and managers."

"Overall I would rate this tool an A."

"Everything about AceProject ended up being very helpful."

\section{INSTRUCTOR COMMENTS}

AceProject is a very effective teaching tool that highlighted three interesting observations from the instructor's point of view. First, some students have a general anxiety about learning technology tools. In this case, it was not a major issue. Students had a sufficient background in computer skills, with all students having been required to complete at least two prior computer information systems and/or management information systems as prerequisites. In a traditional classroom, there would have been more of an opportunity for instructor led assistance with getting started on software use. However, as student become employees, they will continue to find that they must learn new computer based information tools, often almost entirely on their own.

Second, students seemed to have more trouble with the concept of learning an unfamiliar software tool when it was presented at the beginning of the course rather than toward the end of the semester. It may have been a time management issue, they may have felt overwhelmed at using a tool they had not seen before, or there may be some other explanation. Additional research is required to understand this observation. A general rule of thumb may be to make sure that the student, particularly an online course student, is heavily invested in the course before being presented with an assignment that is particularly challenging.

Third, a web-based project management tool has significant advantages over a single site installation. Although many schools have access to single site license copies of Microsoft Project and many textbooks ship with 
a trial version of this software; project management software, by definition, needs to be a server based application that is able to help a group of people communicate and manage tasks associated with a project. AceProject has extensive features to allow all group members, including the instructor, to monitor project progress and to notify group members of new/changed tasks and other changes.

\section{CONCLUSION}

Using AceProject, students have access to an affordable and effective tool to increase their understanding of planning, organizing, controlling, and monitoring projects in a global environment. It is a cost effective way for instructors of project management and other IT management topics to introduce students to server-based project management software without having to buy Microsoft Project licenses or setup a server-based version of Microsoft Project, both of which may be quite expensive. It also has the advantage of being a web-based tool with anytime access by students and instructors

\section{AUTHOR INFORMATION}

Dr. Melinda Cline is an Associate Professor of Management and Information Systems at Georgia Gwinnett College. She received her Ph.D. from Florida State University. Her research interests include information technology investment, organizational change, knowledge-based systems, and international business. She has published articles in the Journal of Information Systems Management, Information Strategy, Decision Support Systems, Computers and Society, Managerial Auditing Journal, Journal of Computer Information Systems and Computer Science Education. mkcline@charter.net.

Dr. C. S. Guynes is a Regents Professor of Information Systems at the University of North Texas. He received a doctorate in quantitative analysis from Texas Tech University. Dr. Guynes' areas of specialization are client/server computing, data administration, and web development. Some of the journals in which Dr. Guynes has published include Communications of the ACM, Information \& Management, The Journal of Information Systems Management, Journal of Accountancy, Journal of Systems Management, The Journal of Database Management, The CPA Journal, The Journal of Computer Information Systems, and Information Strategy. Guynes@unt.edu.

Karine Simard, PMP, is in charge of marketing, customer relations and project management for Websystems, Inc. She is a board member of the Levis-Quebec Chapter of the PMI and writes about project management on the blog Go Ahead, Manage and the PMI's Levis-Quebec Chapter newsletter. Karine.simard@aceproject.com.

\section{REFERENCES}

1. Astin, A.W. (1993). What Matters in College? Four Critical Years Revisited. San Francisco: Jossey-Bass.

2. Chickering, A. W. \& Gamson, Z. F. (1987). Seven Principles for Good Practice in Undergraduate Education. AAHE Bulletin, 39(7), 3-7.

3. Pascarella, E.T. \& Terenzini, P.T. (2005). How College Affects Students: A Third Decade of Research (Vol.2). San Francisco: Jossey-Bass.

4. Project Management Institute (2008). http://www.pmi.org/info/PP OPM3ExecGuide.pdf

5. Wikipedia (2008). http://en.wikipedia.org/wiki/Project management 